\title{
Lighting control network based on KNX protocol, for the reduction of energy consumption
}

\author{
Omar Chamorro-Atalaya ${ }^{1}$, Angel Quesquen-Porras ${ }^{2}$, Dora Arce-Santillan ${ }^{3}$ \\ ${ }^{1,3}$ Facultad de Ingeniería y Gestión (FIG), Universidad Nacional Tecnológica de Lima Sur (UNTELS), Perú \\ ${ }^{2}$ Bticino Legrand Perú, Perú
}

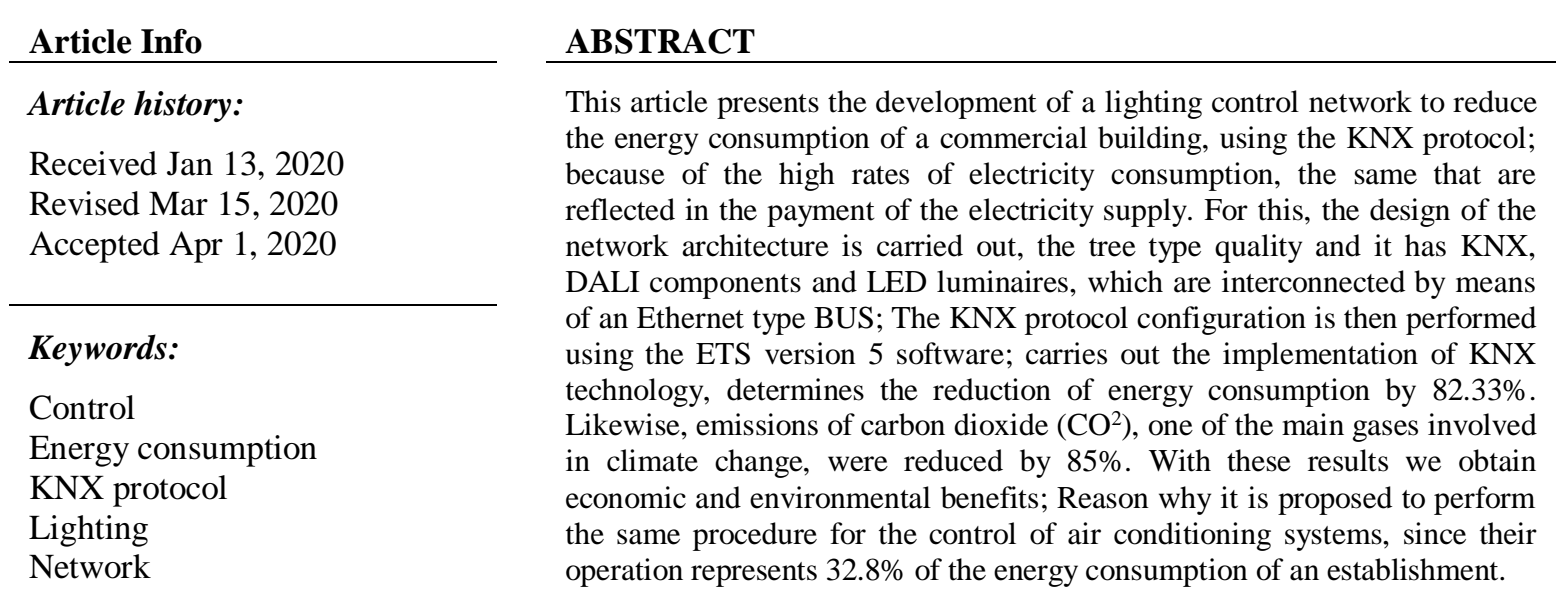

Copyright $\odot 2020$ Institute of Advanced Engineering and Science. All rights reserved.

\section{Corresponding Author:}

Omar Chamorro-Atalaya,

Facultad de Ingeniería y Gestión (FIG),

Universidad Nacional Tecnológica de Lima Sur (UNTELS), Perú.

Email: omar_chamorro1@hotmail.com

\section{INTRODUCTION}

Companies to produce necessary resources, such as energy, raw materials, equipment, technology and information [1]. Many of these institutions constantly use these resources and not always responsibly; generating high emissions of pollutants, due to excessive inefficient consumption levels of lighting and air conditioning equipment [2]. The refrigeration and air conditioning market represents $32.8 \%$ of the total consumption of electrical energy, in addition to its fluids, substances and refrigerants that pollute the environment [3]. While lighting consumption represents $24 \%$ of electric energy billing [4].

As a solution to this, intelligent technology will become one of the necessary facilities for human life [5], the aim of this is to minimize energy consumption and maximize comfort. [6] Ensuring adequate lighting, striving for energy efficiency, as well as increasing comfort and interior design are the reasons for the development of many light sources using various radiation phenomena. Controlling these sources requires the proper selection of controllers that allow for proper connection of sources and smooth adjustment of lighting parameters [7].

The efficient control of energy carriers in smart buildings requires communication protocols that specify the exchange of information between devices and the general monitoring of the property [8]. As stated, today automation systems are widely used in buildings to create smart applications [9]. Therefore there are many automation protocols such as BACnet, C-Bus, CC-link, DALI and KNX [10]. For this, the KNX standard was developed for the design of home automation applications [11]. In addition, the demand for wireless technology has increased due to several advantages, such as reduced installation costs, easy placement, easy extension, 
aesthetic benefits and connectivity of mobile devices [12]. In many real-life scenarios, KNX-enabled devices (sensors and actuators) are controlled with a multifunctional controller or touchpad [13].

The special characteristics of the KNX standard compared to other field buses is, above all, its modernity and its home automation applications [14]. This protocol meets all the requirements to comply with the energy performance classification, that is, the KNX protocol is ideal to meet the adjustment needs of energy consumption in companies and institutions [15], since they allow energy savings of up to $70 \%$ in equipment air conditioning and $89 \%$ in lighting [16]. In that sense, the purpose of this article is to describe an alternative of how to optimize the consumption of electric energy in a commercial building, using a luminaire control network, using the KNX protocol. In order to develop this proposal. I initially present in this article the design of the network architecture, establishing the type of topology and components to be used. The use of KNX components, digital addressable lighting interface (DALI) controllers and LED luminaires, which are interconnected by means of an Ethernet bus, is highlighted. This will also seek to quantify said reduction in energy consumption that is achieved by using the KNX protocol and its partners associated with said technology.

\section{PROCEDURE}

Initially a flow chart is made, in which we will indicate the steps for the procedure to be adopted in relation to the design Figure 1. As indicated in the flowchart of Figure 1, the KNX protocol analysis will initially be performed. The KNX protocol has an independent system. Through the KNX transmission medium (twisted pair, radio frequency, force line or IP/Ethernet), on which all the devices are connected, the communication is exchanged.

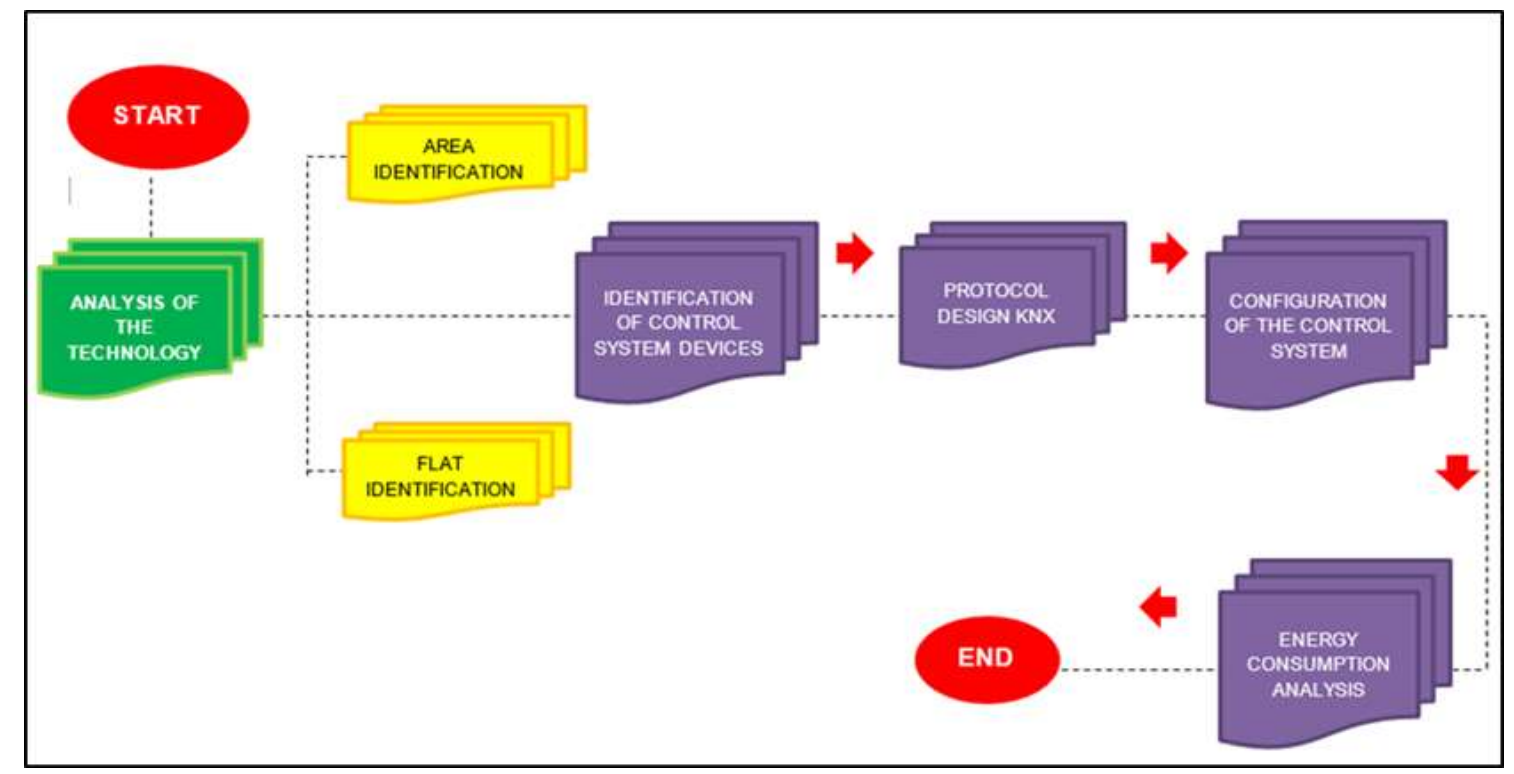

Figure 1. Flowchart of the procedure (own elaboration)

The indications that the control system wiring has are the following:

a) The KNX bus must be powered with a voltage of $29 \mathrm{~V}$.

b) The data is transmitted in serial mode (9600bits/s).

c) Use of a one pair cable $(2 \times 0.8 \mathrm{~mm})$.

d) Maximum distance between two products: $700 \mathrm{~m}$.

e) Maximum distance between a product and the KNX power supply, $350 \mathrm{~m}$.

f) Maximum BUS length: 1000m.

Once the design is described, we will determine the architecture of the lighting control system, using the KNX protocol. For this we will identify the components that are part of this system are shown in Table 1 . As shown in the following table, the components are part of the KNX and DALI protocol, it should be noted that, DALI is an international standard defined by the international electrotechnical commission (IEC) in the IEC 62386 standard.

One of the main advantages of working with DALI protocol it is that it allows planning a lighting installation or system in a more conceptual than physical way with the possibility of easily modifying groups

Lighting control network based on KNX protocol, for the reduction of energy... (Omar Chamorro-Atalaya) 
or scenes at the last moment without having great implications at the operational level (wiring) as happens with other types of systems. In addition, it is a very flexible system because of the possibility of changing groups. A second point would include cost reduction. On the one hand, lower cost in control systems by being able to integrate different products from different manufacturers within the same system. On the other hand, it allows individual control with the consequent energy savings [17]. In this case, the network architecture presents DALI controllers, for the activation of the luminaires. Once the components of the KNX protocol have been identified, the control architecture is shown below. It should be noted that the design is being made for a three-story commercial building.

Table 1. Symbology of the components of a KNX network

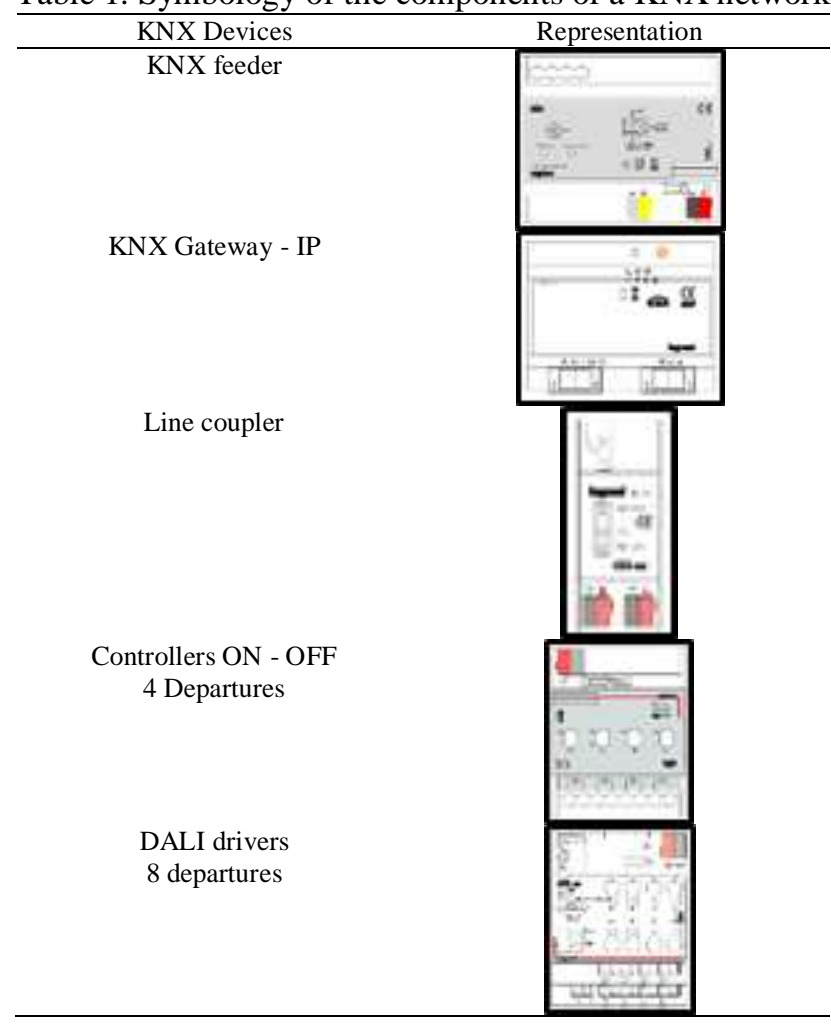

As seen in Figure 2. The network architecture has the following characteristics:

a) The system is independent but integrated to the other levels through the line couplers.

b) Each environment has a main KNX power supply, a DALI controller with 8 outputs and an ON-OFF controller with 04 outputs, 3 PIR Motion sensors, 3 LED Downlight and 3 LED Spot, which are connected to the stage commands and simple command; through KNX couplers, by means of a KNX BUS cable.

c) These devices are connected to a general power supply and a Gateway, for integration into the Ethernet network.

d) A USB interface is used to allow the configuration of KNX devices from a PC with ETS software version 5.

e) The wiring of the KNX system can be configured as that of the power line, in this case, it is a tree type.

f) Buses, control consumer devices, are available for DIN rail mounting. The bus components can always be installed where it is best suited within the installation, so they are always guaranteed to be optimally used.

g) In this way, it is possible to evaluate or vary the main aspects of the system according to the way of placing the components.

Next, the ETS software configuration is done; The steps for configuring the control system are as follows:

Step 1: The project is created in the ETS V5 Software.

Step 2: Project levels are determined.

Step 3: Choose the product to be configured from the catalog and drag it to the main board.

Step 4: The device configuration is determined.

Step 5: The configuration is loaded, for this purpose it is sent through the "program" function, and a USB type cable is connected-from the PC to the USB interface in Figure 3. This procedure is observed. 


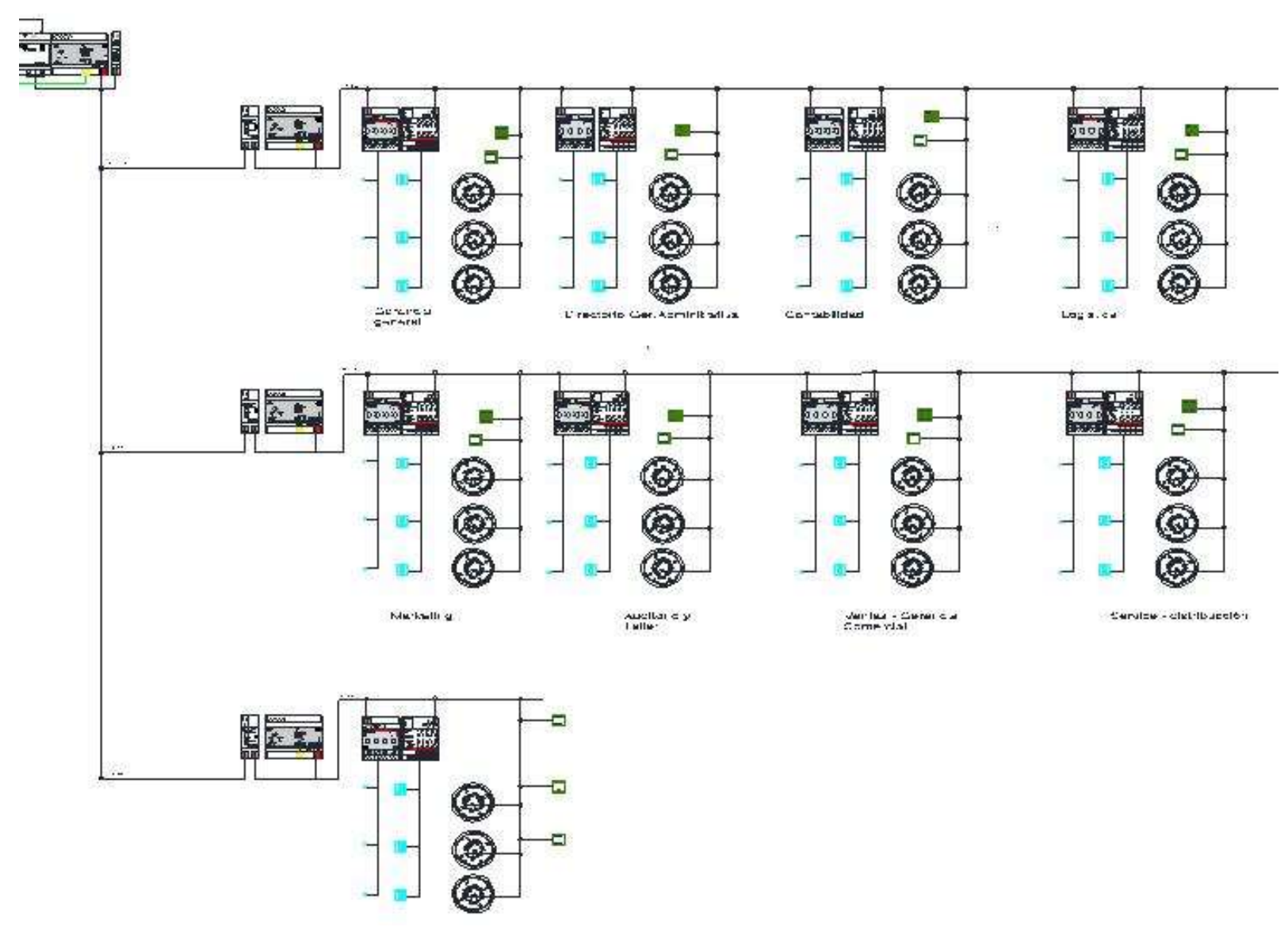

Figure 2. KNX control system architecture

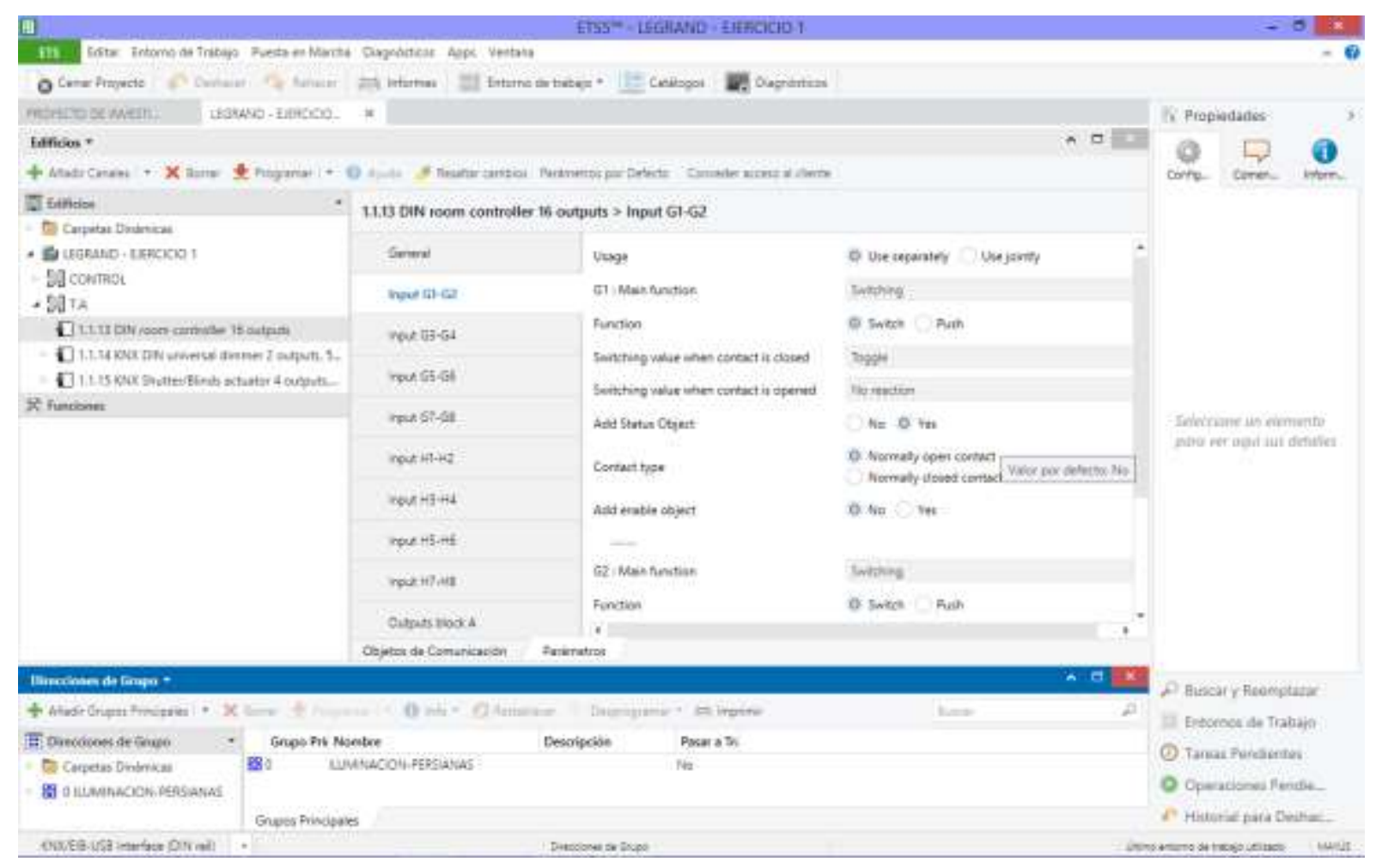

Figure 3. Load device configuration (ETS V5)

Lighting control network based on KNX protocol, for the reduction of energy... (Omar Chamorro-Atalaya) 


\section{RESEARCH METHOD}

\subsection{Research level}

The investigation will be descriptive; since, we will analyze the results of electric power consumption, after the implementation of the luminaire control system, based on the KNX protocol. That is, they only intend to measure or collect information independently or jointly and draw a conclusion from it [18].

\subsection{Population and sample}

The population in this investigation is represented by the luminaire system of the offices of the commercial building, which has 3 floors. The analysis of the light calculation will be carried out on each of the floors, since it has independent electrical panels. Also, the sample will be the same as the population; since, if the population is less than fifty (50), the population is equal to the sample [19].

\subsection{Data collection}

The instrument used is the measurement data sheet, in which the results of the electric power consumption of the year 2019 have been collected.

\section{RESULTS AND DISCUSSION}

\subsection{Results}

Once the lighting control system based on the KNX protocol has been implemented, and the measurement data has been collected, the analysis of the electric power consumption will be carried out. Table 2 shows the total energy consumption before implementing the KNX protocol. As can be seen, before implementing the KNX protocol, a total of $130,572,672 \mathrm{KWh}$ was consumed. If the KWh in Peru equals 0.1967 , this means that the company spent S/.25,683.65. In addition to being a high economic expense, it also represented $6,500 \mathrm{~kg}$ of $\mathrm{CO}^{2}$ emission. These reasons were the root to develop the proposed solution. Now in Table 3, we will see the results of electric power consumption, once the KNX protocol system has been implemented.

Table 2. Energy consumption in the year 2018 without the protocol KNX

\begin{tabular}{cccc}
\hline Dispositives & $\begin{array}{c}\text { Potence } \\
\text { KW }\end{array}$ & $\begin{array}{c}\text { Annual } \\
\text { consumption } \\
\text { hours }\end{array}$ & $\begin{array}{c}\text { Total power } \\
\text { consumption } \\
\text { KWh }\end{array}$ \\
\hline $\begin{array}{c}\text { Dichroic } \\
\text { lamps }\end{array}$ & 5.552 & 8,616 & $47,836.032$ \\
$\begin{array}{c}\text { Fluorescents } \\
\text { 9.576 }\end{array}$ & 8,640 & $\begin{array}{c}82,736.64 \\
130,572.672\end{array}$ \\
\hline
\end{tabular}

Table 3. Energy consumption in the year 2019 with the protocol KNX

\begin{tabular}{cccc}
\hline Dispositives & $\begin{array}{c}\text { Potence } \\
\text { KW }\end{array}$ & $\begin{array}{c}\text { Annual } \\
\text { consumption } \\
\text { hours }\end{array}$ & $\begin{array}{c}\text { Total power } \\
\text { consumption } \\
\text { KWh }\end{array}$ \\
\hline Spot LED & 1.2 & 6,980 & $8,376.00$ \\
Dowlight & 2.1 & 6,998 & $14,695.80$ \\
LED & & & $23,071.80$ \\
\hline
\end{tabular}

As can be seen, with the KNX protocol, the energy consumption is 23,071.80, equivalent to $\mathrm{S} / 4,538.22$. Also, because the energy consumption of LED lamps is much lower than other luminaires, carbon dioxide $\left(\mathrm{CO}^{2}\right)$ emissions, one of the main gases involved in climate change, are reduced by $85 \%$ [20], being the current value of $\mathrm{CO} 2$ of $5525 \mathrm{Kg}$. To determine by what percentage the energy consumption has been reduced as shown Figure 4, we will use the following formula; which consists in calculating the average for each of the groups (without the KNX protocol and with the KNX protocol), the difference, will be the percentage of reduction of the consumption of electrical energy.

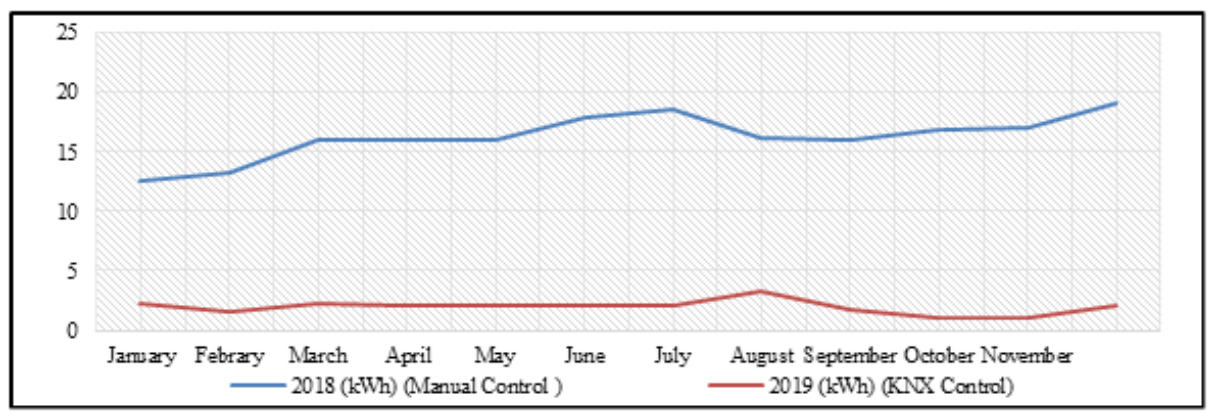

Figure 4. Monthly electricity consumption 2018-2019 


$$
\% \text { reduction }=\frac{M S P-M C P}{M C P} \times 100
$$

where:

$\%$ reduction = Energy consumption reduction percentage

MSP = Media without protocol KNX

MCP = Media with protocol KNX

Once the energy consumption values of Tables 2 and 3 are obtained, we will calculate the average of both values; obtaining as a result the following:

$$
\% \text { reduction }=\frac{11,535.90-65,286.336}{65,286.336} \times 100 \%=-82.33 \%
$$

As noted, the value of energy consumption has been reduced to 82.33 ; this value being very beneficial for the company and for the environment. Finally, we will determine the level of significance of the reduction result, using the T-Student test in Table 4. This test is used when the following requirements are met [21].

a) When it is possible to calculate the mean and standard deviation from the sample.

b) The sample size must be less than 30 .

Table 4. T-student test

\begin{tabular}{lccc}
\hline & Sig. (bilateral) & 95\% difference confidence interval \\
& & Lower & Upper \\
\hline Energy consumption_2018 &, 000 & 10,48860 & 11,27340 \\
Energy consumption_2019 &, 000 & 1,56208 & 2,28309 \\
\hline
\end{tabular}

In the T-Student test, we will focus on the significance (bilateral), according to the theory so that it has a highly significant value must be less than the alpha, that is [22].

a) If the probability obtained P-value (Sig. Bilateral) $\leq \alpha(0.05)$; the reduction is highly significant

b) If the probability obtained P-value (Sig. Bilateral) $>\alpha(0.05)$, the reduction is not significant

As can be seen in the result of Table 4 the (bilateral) significance of the reduction in energy consumption is highly significant, because the (bilateral) significance obtained (0.000); It is less than $\alpha$ (0.05). This statistical test corroborates the calculation of the formula (1), where it is obtained that the reduction of the energy consumption $(\mathrm{KWh})$ of the luminaires once the KNX protocol has been implemented, has been reduced by $82.33 \%$.

\subsection{Discussions}

In relation to the reduction of energy consumption, this supports the study carried out in Venezuela, where the results indicate that the installation of a KNX programmable system (10,300 BUS devices installed) allowed a saving of 122,045 euros [23]. Also, in the investigation carried out for a distribution center of $4000 \mathrm{~m}^{2}$ of area; it is concluded that the designed control system, under a strategy of light compensation with natural light incidence, allows to improve the energy efficiency of the lighting system by reducing energy consumption by $26 \%$, which translates into savings in economic terms in addition, the KNX protocol allows reducing the annual energy consumption cost associated with the lighting system, from $\mathrm{S} / 6,392.65(20,391.24 \mathrm{Kw} / \mathrm{h})$ at $\mathrm{S} / 4,730.56(15,089.52 \mathrm{Kw} / \mathrm{h})$, generating savings of $\mathrm{S} / .1,662.09$ (considering the cost of $1 \mathrm{Kw} / \mathrm{h}$ in $\mathrm{S} / 0.30$ ) [24]. The results support the research entitled activation of functions in intelligent buildings using voice commands from mobile devices; where it is pointed out that it was possible to obtain a functional prototype of the home automation system, which serves as an interface between users and devices connected to a KNX network, managing to execute voice commands within it. The tests performed on access through the list of commands showed a system reliability of 99\% [25]. Likewise, the research carried out at the José Francisco de Caldas District University, indicates that, the home automation control system developed has the capacity to reduce the waste of electric energy produced by the consumption habits of people living in a home, when carrying out the control and management of your lighting system, with a saving of about $3.75 \%$ of the total consumption, which is a significant value taking into account the variability of the consumption of previous months (sigma $=6.83 \mathrm{kWh}$ ) and the typified unit of consumption with the home automation system $(\mathrm{z}=-1.93)$ [26]. The KNX protocol is $15 \%$ more efficient than the CC-link protocol [27], KNX showed better results than C-Bus, this due to its multiple domotic applications and specialization in energy efficiency [28]

Lighting control network based on KNX protocol, for the reduction of energy... (Omar Chamorro-Atalaya) 


\section{CONCLUSION}

It is concluded that through the implementation of the KNX protocol, energy consumption was reduced by $82.33 \%$, with annual energy consumption being $23,071.80$, equivalent to S/.4,538.22. Likewise, carbon dioxide $\left(\mathrm{CO}^{2}\right)$ emissions, one of the main gases involved in climate change, are reduced by $85 \%$, with the current $\mathrm{CO}^{2}$ value of $5525 \mathrm{Kg}$. It is concluded that the network architecture of the lighting control system was designed, using the KNX protocol, whose topology is of tree type and among its devices it has $4 \mathrm{KNX}$ feeder, 1 KNX-IP gateway, line couplers, On-Off controllers, DALI with 4 and 8 outputs respectively, LED panel, LED downlight, LED spot and PIR motion detectors.

\section{ACKNOWLEDGEMENTS}

The authors wish to recognize and thank to the company Bticino Legrand Peru, for their support of this investigation

\section{REFERENCES}

[1] J. Goltz, T. Mundt and S.Wiedenmann, "Risk Analysis in Fieldbus Networks Using the Example of KNX," 2019 International Conference on Information Networking (ICOIN), Kuala Lumpur, Malaysia, pp. 310-315, 2019.

[2] S. Sowa and J. Gielniak, "Implementation of the lighting control algorithms in the KNX system," ITM Web of Conferences, vol. 19, no. 01040, 2018.

[3] A. Kartuzov, T. Kartuzova \& L. Seliverstova, "Laboratory stand for designing industrial KNX networks on Siemens logo! Communication modules," E3S Web of Conferences EECE 2019, vol. 140, no. 04008, 2019.

[4] G. Bovet and J. Hennebertm, "A Web-of-Things Gateway for KNX Networks," Smart SysTech 2013; European Conference on Smart Objects, Systems and Technologies, Erlangen/Nuremberg, Germany, pp. 1-8, 2013.

[5] F. Elyes, K. Kassab and A. Mami, "Integration of the small board computers Raspberry PI in Home Automation based on KNX protocol," ITM Web of Conferences, El Manar, Tunisia, 2019.

[6] D. Piña, R. Araguez and I. Benitez, "KNX un paso más hacia los edificios del futuro KNX one more step towards the buildings of the future," International Conference on Information Networking (ICOIN), Habana, Cuba, 2018.

[7] M. Toylan and E. Cetin, "Design and application of a KNX-based home automation simulator for smart home system education," Computer Applications in Engineering Education, vol. 27, no. 4, 2019.

[8] A. A. López, S. A. Navarro, M. R. Bustamante, J. Izquierdo Reyes and L. A. Curiel, "Interpretation and Emulation for Telegrams of the KNX Standard on MATLAB Simulink," 2018 International Conference on Mechatronics, Electronics and Automotive Engineering (ICMEAE), Cuernavaca, Mexico, pp. 129-133, 2018.

[9] S. Seifried, G. Gridling and W. Kastner, "KNX IPv6: Design issues and proposed architecture," 2017 IEEE 13th International Workshop on Factory Communication Systems (WFCS), Trondheim, Norway, pp. 1-10, 2017.

[10] D. Typanska, A. Maćkowiak \& K. Sieczkarek. "The immunity of the KNX model to continuous electromagnetic disturbances," Przeglad Elektrotechniczny, vol. 92, no. 9, pp. 243-245, 2016.

[11] W. Suk and S. Ho, "Design and Implementation of KNX-ZigBee Gateway," Journal of Institute of Control, vol. 17, no. 7, pp. 720-729, 2011.

[12] D. Typanska, "The Immunity of the KNX Model to Electromagnetic Pulse Disturbances," Prezeglad Elekrotechniczny, vol. 1, no. 4, pp. 40-43, 2016.

[13] S. Cavalieri and G. Cutuli, "Realising Secured Data Transmission in KNX," 2009 7th IEEE International Conference on Industrial Informatics, Cardiff, Wales, pp. 626-531, 2009.

[14] J. Dzmura, J. Petrás and M. Bernát, "Physical parameter measurement by KNX/EIB system," Computer Applications in Engineering Education, 2016.

[15] W. Suk Lee and S. Ho Hong, "KNX-ZigBee gateway for home automation," 2008 IEEE International Conference on Automation Science and Engineering, Arlington, VA, pp. 750-755, 2008.

[16] J. Vanus, M. Cerny and J. Koziorek, "The proposal of the smart home care solution with KNX components," 2015 38th International Conference on Telecommunications and Signal Processing (TSP), Prague, pp. 1-5, 2015.

[17] A. Burak, S. Akin and O. Urhan, "Touch Panel Design for KNX Home Automation System," 14th International Conference on Telecommunications and Informatics, Kocaeli, Turkey, 2015.

[18] G. Bonilla and Y. Sirit, "Experimental Design for Civil Engineers," Engineering Magazine, Caracas, Venezuela, 2016.

[19] J. Salazar and A. Baena, "Analysis and design of experiments applied to simulation studies," Dyna (Medellin, Colombia), vol. 76, no. 159, pp. 249-257, 2009.

[20] J. Vanus, O. Majidzadeh and P. Bilik, "Novel Proposal for Prediction of CO2 Course and Occupancy Recognition in Intelligent Buildings within IoT," Energies, vol. 12, no. 23, pp. 4541-4566, 2019.

[21] A. Gallego and R. Gonzales, "Medotología de la Investigación en Ingeniería," Revista Científica, vol. 29, no. 2, pp. $115,2016$.

[22] O. Atalaya, D. Santillan, and J. Bedriñana, "The correlation of the specific and global performance of teachers in UNTELS engineering schools," Advances in Science Technology and Engineering Systems, vol. 4, no. 6, pp. 196-202, 2019.

[23] J. Vásquez, "Energy saving in homes in countries with tropical climates ", University, Science and Technology, vol. 10, no. 40, pp. 245-253, 2016

[24] L. Salazar, V. Guzmán and A. Bueno, “Analysis of energy saving measures in a production company”. Ingenius. Science and Technology Magazine, vol. 19, pp. 40-50, 2018 
[25] E. Parada, E., M. Illera, S. Sepúlveda, D. Guevara and B. Delgado, "Low cost home automation system: a support to the ecological electricity generation in Colombia," Journal Tecnura, vol. 20, no. 49, pp.120-132, 2016.

[26] J. Nazábal, F. Falcone, C. Fernández and S. Mukhopadhyay, “Accessing KNX devices using USB/KNX interfaces for remote monitoring and storing sensor data," International Journal of Smart Home, vol. 7, no. 2, pp.105-110, 2013.

[27] M. Hussain, D. Gachet and J. Angulo, "KNX bus automation, a unique infrastructure for all services," Dyna (Bilbao), vol. 86, no. 6, pp. 671-675, 2011.

[28] Y. Hu, N. Han and D. Yan, "The Research and Implementation of KNX Communication Kernel Based on ATMega32," Advanced Materials Research, vol. 433-440, pp. 3269-3275, 2012.

\section{BIOGRAPHIES OF AUTHORS}

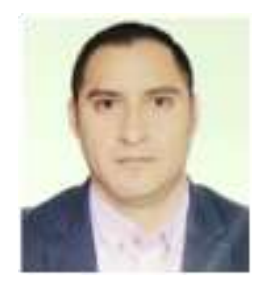

Omar Freddy Chamorro Atalaya is Electronic engineer, school and enabled with master's degree in systems engineering, with more than 15 years of continuous experience in the university chair, in public and private university. Master teacher in the industrial automation course. Professional experience in industrial network automation projects in drinking water systems. Author of several scientific articles in journals indexed in Scopus, in different areas, such as: Supervision and Process Control, Industrial Automation, Solar Panels, Automation of Fire Systems, implementation of Base Stations of Communications 4G-LTE and Behavioral Sciences.

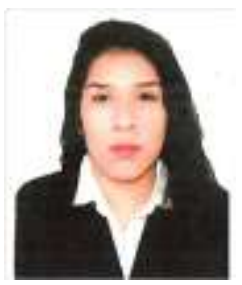

Dora Yvonne Arce Santillan is graduated electrician mechanical engineer at the Universidad Nacional de Lima Sur, colleged and enabled. With studies of Master in Electrical Engineering with mention in Project Management. Author of several scientific articles in journals indexed in Scopus, in different areas, such as: Supervision and Process Control, Industrial Automation, Solar Panels, Automation of Fire Systems and Behavioral Sciences.

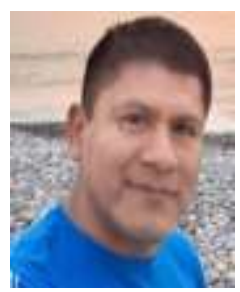

Ángel Hernan Quesquen Porras, Electronic and Telecommunications Engineering, specialist in lighting control systems with KNX technology; He currently works at the company Bticino Legrand Peru, which proposes solutions for the distribution of energy, for communication, as well as for the control of light, sound, climate and safety. 